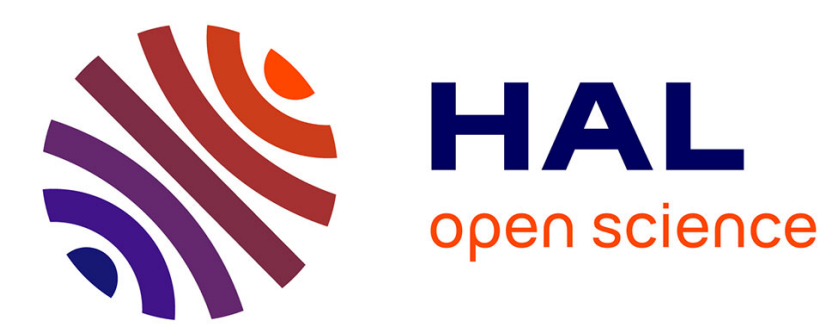

\title{
Effects of waves on the initiation of headland-associated sandbanks
}

\author{
Nicolas Guillou, Georges Chapalain
}

\section{To cite this version:}

Nicolas Guillou, Georges Chapalain. Effects of waves on the initiation of headland-associated sandbanks. Continental Shelf Research, 2011, 31 (11), pp.1202-1213. 10.1016/j.csr.2011.04.013 . hal01673393

\section{HAL Id: hal-01673393 \\ https://hal.science/hal-01673393}

Submitted on 20 Mar 2019

HAL is a multi-disciplinary open access archive for the deposit and dissemination of scientific research documents, whether they are published or not. The documents may come from teaching and research institutions in France or abroad, or from public or private research centers.
L'archive ouverte pluridisciplinaire $\mathbf{H A L}$, est destinée au dépôt et à la diffusion de documents scientifiques de niveau recherche, publiés ou non, émanant des établissements d'enseignement et de recherche français ou étrangers, des laboratoires publics ou privés. 


\title{
Effects of Waves on the Initiation of Headland-Associated Sandbanks
}

\author{
Nicolas Guillou ${ }^{\mathrm{a}, *}$, Georges Chapalain ${ }^{\mathrm{a}}$ \\ ${ }^{a}$ Laboratoire de Génie Côtier et Environnement, Centre d'Etudes Techniques Maritimes Et Fluviales, \\ 155 rue Pierre Bouguer, Technopôle Brest-Iroise, BP 5, 29280 Plouzané, France.
}

\begin{abstract}
Linear sandbanks appear in the lee of coastal headlands where the hydrodynamics are dominated by strong tidal current and the seabed is characterized by an abundance of sands. They may develop as symmetrical sandbanks on either sides of the headland or as an unique banner bank. The present study numerically investigates the combined effects of waves and tide on the initial development of headland-associated sandbanks. A morphological model based on the coupling of the wave propagation module SWAN (Simulating WAves Nearshore) with the three-dimensional circulation module COHERENS (COupled Hydrodynamical-Ecological model for REgioNal and Shelf seas) is applied to an idealised Gausssian shaped headland for waves conditions varying in heights and directions at the offshore boundary. The coupling considers the effects of the interactions between the wave and current bottom boundary layers, namely the enhanced levels of turbulence near the bottom and the increase of the total bottom shear stress. Waves substantially modify the initial development of sandbanks formed by suspension narrowing their width and reorienting them along the side of the headland. They weakly impact the morphogenesis of sandbanks by bedload favoring on a short time scale the growth of symmetric circular-shaped features and a central depositional spit prolonging the headland tip. Waves of transverse directions towards the tip of the headland contribute to the initiation by suspension of a well-developed feature in the headland side of low energy limiting the seabed evolution in the exposed area.
\end{abstract}

Keywords: sandbanks, headland, numerical modelling, waves, tide, bedload, suspension

\footnotetext{
* Corresponding author

Email addresses: nicolas.guillou@developpement-durable.gouv.fr (Nicolas Guillou), georges.chapalain@developpement-durable.gouv.fr (Georges Chapalain)

Preprint submitted to Continental Shelf Research 


\section{Introduction}

Coastal irregularities are known to favor the flow separation creating transient eddies liable to trap nearshore sediment fluxes and to form bed features (Westrich, 1976; Ferentinos and Collins, 1980). Large sandbanks between 5 and 30 kilometers length and 1 and 2 kilometers width are thus appearing in the vicinity of coastal headlands where the hydrodynamics are dominated by strong tidal currents and the seabed is characterized by an abundance of sand (Pattiaratchi and Collins, 1987). This type of bed features classified by Dyer and Huntley (1999) as headland-associated sandbanks usually develops on one side of the headland as a single banner bank. Illustrations of this morphological development are given in the bank of Gay Head off Massachusetts (United-States) (Geyer, 1993), the Shambles Bank near Portland Bill (United-Kingdom) (Pingree, 1978; Bastos et al., 2004) and the Levillain Shoal near Cape Levillain (Western Australia) (Berthot and Pattiaratchi, 2005, 2006a).

Various theories have been advanced to explain the formation and maintenance of a well-developed banner bank on one side of the headland. A review of these concepts is available in Dyer and Huntley (1999). One popular hypothesis proposed by Pingree (1978) suggested that the sand would accumulate at the centre of the residual eddies generated on either sides of the headland by reversing tidal flows. According to this theory, the balance between the Coriolis and centrifugal forces would control the magnitude of sediment deposition and gives preferential development of sandbanks at the centre of the cyclonic eddy. Signell and Harris (2000) recently disproved this theory using a numerical sediment transport model applied to an idealized Gaussian shaped headland in tide-dominated conditions. Their simulations resulted in the formation of symmetric sandbanks on either sides of the headland for both northern and southern hemispheres revealing a negligible influence of the Earth's rotation. These results exhibited the weak relevance of the tidally-averaged residual fields to characterize the formation of headlandassociated sandbanks as the morphodynamic evolution was predominantly influenced by the patterns of the shear stress and the sediment fluxes over the course of the tidal cycle. Fields measurements undertaken by Berthot and Pattiaratchi (2006a) around Cape Levillain showed that a very strong inequality in the tidal signal might explain the difference between the well-developed Levillain Shoal and less developed symmetrical bank on the headland's northern side. More recently, Roos et al. (2004) and Berthot and Pattiaratchi (2006b) proposed to include the effect of the waves as a damping mechanism for the growth rate and possible development of banner banks.

The purpose of the present study is to numerically investigate the combined action of waves and tide on the initial development of headland-associated sandbanks. The analysis is limited to the initiations of erosional and depositional patterns by bedload and suspension load of bottom sediments. To be concordant with previous work undertaken by Signell and Harris (2000) and Berthot and Pattiaratchi (2006b), the application is dedicated to an idealised Gaussian shaped headland adapted from the case of Gay Head (Massachusetts).

A three-dimensional (3D) numerical approach is suggested as complex 3D current patterns are generated in the vicinity of the headland (e.g., Berthot and Pattiaratchi, 2006a). The hydrodynamic modelling is based on the coupling of a wave propagation module (section 2.2) with a 3D circulation module (section 2.3). The coupling is restricted to the effects of the interaction between the wave and current bottom boundary layers 
leading to enhancements of the magnitudes of the bed shear stress and the near-bottom viscosity (Grant and Madsen, 1979). The hydrodynamic forcings are then integrated in the sediment transport module for the computations of bedload, suspension load and the morphological evolutions (section 2.4). Computations are performed for two beds of uniform single grain size considering successively the bedload of medium sands $\left(d_{b}=\right.$ $250 \mu \mathrm{m})$ and the suspension load of silts $\left(d_{s}=30 \mu \mathrm{m}\right)$ (section 3.1). The analysis compares the predicted fields of the depth-averaged current, the total bottom shear stress and the short term morphological evolution for conditions of tide alone (section 3.2 ) and combined tide and waves (section 3.3).

\section{Model Description}

The modelling procedure is conducted in three steps successively dedicated to the hydrodynamics, the sediment transport and the morphological evolution. The hydrodynamic computation is based on the coupling of the wave propagation module SWAN (Simulating WAves Nearshore) (Booij et al., 1999) with the hydrodynamic kernel of the 3D circulation module COHERENS (COupled Hydrodynamical-Ecological model for REgioNal and Shelf seas) (Luyten et al., 1999). The sediment transport modelling is based on (i) a simple semi-empirical formulae to compute bedload and (ii) a 3D single class advection-diffusion equation to compute suspended load. The model progresses through this numerical sequence to predict a new bed topography on the basis of a two-dimensional sediment budget equation.

\subsection{Assumptions}

The flow is assumed to be turbulent over a featureless rough bottom characterized by the roughness parameter $z_{0}$ defined as the height above the bottom at which the fluid velocity is zero. Sedimentary particles are taken spherical with an uniform grainsize diameter, non-cohesive and made of quartz with density $\rho_{s}=2650 \mathrm{~kg} \mathrm{~m}^{-3}$. The porosity of the bed is set to $p=0.35$. Two modes of sediment transportation are considered: bedload and suspended load. They are computed separately initializing the bed with a single size class of diameters equal to $d_{b}$ for bedload and $d_{s}$ for suspended load. Neglecting the effects of the interactions between solid particles, the water-sediment mixture is assumed homogeneous with a density $\rho=1025 \mathrm{~kg} \mathrm{~m}^{-3}$ of clear water, a temperature $T=10{ }^{\circ} \mathrm{C}$ and a salinity $S=35 \mathrm{psu}$, practical salinity units. Further details about these assumptions are available in Guillou et al. (2009) and Guillou and Chapalain (2010). Finally, the coupling between waves and currents is restricted to the interaction of the wave and current bottom boundary layers and their effects on the bottom shear stress and the level of turbulence near the bottom. The modelling procedure ignored the modifications of the waves components by the current and the free-surface elevation and the generation of currents by waves.

\subsection{Waves (SWAN)}

SWAN solves the time-independent spectral action balance equation (Booij et al., 1999). The present modelling accounts for (i) depth shoaling and refraction, (ii) nonlinear transfer of energy through wave-wave interactions and (iii) wave decay due to bottom friction and depth-induced breaking. The bore-based model of Battjes and Janssen (1978) 
is used to model the energy dissipation in random waves due to depth-induced breaking. The eddy-viscosity model of Madsen et al. (1988) is retained to parametrize the sink term of dissipation by bottom friction. The model runs in stationary mode as the effects of time-varying water depths and ambient currents are ignored. The wave action balance equation is expressed in a Cartesian coordinate system $(x, y)$. Further details about the mathematical expressions of sources and sink terms are available in SWAN team (2009).

\subsection{Circulation (COHERENS)}

COHERENS solves the continuity equation and the Reynolds-averaged momentum equations derived using the Boussinesq's $(1823,1903)$ approximations and the vertical hydrostatic equilibrium. The horizontal eddy viscosity $\nu_{H}$ is parametrized following Smagorinsky (1963). The vertical eddy viscosity is expressed as $\nu_{T}=0.108 k^{2} / \varepsilon$ where $k$ is the turbulent kinetic energy and $\varepsilon$ is its dissipation rate. These turbulent moments are obtained by solving a pair of transport equations which are well-known as the $k-\varepsilon$ turbulence closure scheme (e.g., Launder and Spalding, 1974). The momentum and turbulent equations are subjected to bottom boundary conditions derived from the law of the wall. The essential features of the interactions between the wave and current bottom boundary layers are computed according to Grant and Madsen (1979), namely (i) the increase of the apparent roughness parameter $z_{0 c}$ felt by the current above the wave boundary layer, (ii) the total maximum wave and current bottom shear stress $\tau_{b, c w}^{\max }$ and (iii) the enhanced levels of turbulence and the vertical eddy viscosity $\nu_{T}$ near the bottom. The set of equations is expressed in a horizontal Cartesian coordinate system with a vertical $\sigma$ coordinate transformation. Further details about the circulation module are given by Luyten et al. (1999) and Guillou (2007).

\subsection{Sediment (COHERENS)}

Suspension load is computed using a concentration-based approach where the instantaneous suspended sediment concentration (SSC) $C_{s}$ of particles of grain-size diameter $d_{s}$ satisfies the $3 \mathrm{D}$ advection-diffusion transport equation

$$
\begin{array}{r}
\frac{\partial H C_{s}}{\partial t}+\frac{\partial}{\partial x}\left[H\left(u C_{s}-\lambda_{H} \frac{\partial C_{s}}{\partial x}\right)\right]+\frac{\partial}{\partial y}\left[H\left(v C_{s}-\lambda_{H} \frac{\partial C_{s}}{\partial y}\right)\right] \\
+\frac{\partial}{\partial \sigma}\left[\left(\tilde{w}-w_{s}\right) C_{s}\right]=\frac{\partial}{\partial \sigma}\left(\frac{\lambda_{T}}{H} \frac{\partial C_{s}}{\partial \sigma}\right)
\end{array}
$$

where $t$ denotes time, $(u, v)$ are the horizontal velocity components along $x$ and $y$ respectively, $H$ is the instantaneous total water depth, $\tilde{w}$ is the vertical velocity normal to $\sigma$-planes, $\lambda_{H}$ is the horizontal eddy diffusivity parametrized following Smagorinsky (1963) and $\lambda_{T}$ is the vertical eddy diffusivity expressed as $\lambda_{T}=0.177 k^{2} / \varepsilon$. Finally, $w_{s}$ is the settling velocity given by the Soulsby's (1997) formulation.

A zero mass flux condition is imposed at the free-surface. The bottom boundary condition which specifies the net mass flux through the bottom level of suspension is the difference between the deposition rate $D_{s}$ due to settling and the upward turbulent entrainment rate $E_{s}$ :

$$
w_{s} C_{s}+\frac{\lambda_{T}}{H} \frac{\partial C_{s}}{\partial \sigma}=D_{s}-E_{s} .
$$


The deposition rate is simply expressed as

$$
D_{s}=w_{s} C_{s}^{b o t}
$$

where $C_{s}^{b o t}$ is the near-bed SSC (e.g., Lick, 1982; Lavelle et al., 1984; Chapalain and Thais, 2000).

The entrainment rate is specified following Van Rijn (1986), Celik and Rodi (1988, 1991) and Chapalain and Thais (2000). It is based on the physical hypothesis that the flow always entrains as much sediment from the seabed as it can with the energy available. This implies that, for a situation with a loose bed of unlimited sediment material supply, the entrainment always occurs as its maximum rate. This entrainment rate under full capacity equilibrium situation (i.e., zero net flux across the bottom corresponding to a balance between deposition and entrainment) is

$$
E_{s}=w_{s} C_{s}^{r e f}
$$

where the maximum equilibrium near-bed reference $\operatorname{SSC} C_{s}^{r e f}$ is given by the semiempirical expression of Smith and Lean (1977)

$$
C_{s}^{r e f}=C_{b}\left(\frac{\gamma_{0} T_{s}}{1+\gamma_{0} T_{s}}\right)
$$

$C_{b}=0.65$ is the total volume concentration of sediment in the settled bed (1-porosity). Computations are performed with a resuspension parameter $\gamma_{0}=5.5 \times 10^{-4}$ found to give a good agreement between predicted and measured total SSC in operational applications off Hardelot Beach in the south of Boulogne-sur-Mer in the eastern English Channel (Guillou et al., 2009). $T_{s}$ is the local normalized excess shear-stress between (i) $\tau_{b, c w}^{\max }$ the module of the total maximum wave and current skin bottom shear stress and (ii) $\tau_{c r}$ the critical value above which sediment particles of diameter $d_{s}$ are moved given by the Soulsby and Whitehouse's (1997) formulation. Further details about the suspended sediment transport module are available in Guillou et al. (2009) and Guillou and Chapalain (2010).

Bedload is computed with the formulation proposed by Soulsby and Van Rijn (e.g., Soulsby, 1997) in combined waves and currents conditions. The instantaneous bedload transport rate is given by

$$
\begin{gathered}
\mathbf{q}_{b}=A_{s b} \bar{u}\left[\left(\bar{u}^{2}+\frac{0.018}{C_{D}} \frac{u_{b, r m s}^{2}}{2}\right)^{1 / 2}-\bar{u}_{c r}\right]^{2.4} \\
\text { where } A_{s b}=\frac{0.005 H\left(d_{b} / H\right)^{1.2}}{\left[(s-1) g d_{b}\right]^{1.2}} \\
C_{D}=\left[\frac{0.40}{\ln \left(H / z_{0}\right)-1}\right]^{2} \\
\text { and } \quad \bar{u}_{c r}=0.19\left(d_{b}\right)^{0.1} \log _{10}\left(\frac{4 H}{d_{b}}\right) \\
5
\end{gathered}
$$


$C_{D}$ is the drag coefficient due to current alone, $s=\rho_{s} / \rho$ is the relative sediment density, $\bar{u}_{c r}$ is the threshold current velocity for sediment grain size $d_{b}$ between 100 and $500 \mu \mathrm{m}$, $u_{b, r m s}$ is the root-mean-square wave orbital velocity provided by SWAN and $H$ and $\bar{u}$ are the total water depth and the horizontal depth-averaged current velocity provided by COHERENS, respectively.

The resulting evolution of the seabed is computed by solving the two-dimensional sediment budget equations for bedload

$$
\frac{\partial \xi_{b}}{\partial t}=-\frac{1}{1-p}\left(\frac{\partial q_{b x}}{\partial x}+\frac{\partial q_{b y}}{\partial y}\right)
$$

and suspended load

$$
\frac{\partial \xi_{s}}{\partial t}=-\frac{1}{1-p}\left(E_{s}-D_{s}\right)
$$

where $\left(q_{b x}, q_{b y}\right)$ are the horizontal components of the bedload transport rate $\mathbf{q}_{b}$ (Eq. 6) and $\xi_{b}$ and $\xi_{s}$ are the bed levels resulting from bedload and suspended load, respectively.

\subsection{Numerical Methods}

SWAN time-independent 2D spectral action balance equation is solved on a regular staggered grid, a constant directional resolution and an exponential frequency distribution with an implicit time discretization Euler technique. Further details about the boundary conditions and the numerical schemes are available in SWAN team (2009).

COHERENS circulation and sediment transport equations are solved on a regular staggered grid with numerical schemes for time and space discretizations issued from the standard version of the code (Luyten et al., 1999). Two main modifications have been implemented in relation with the open boundary conditions and the near bottom vertical resolution. The first modification consists in imposing (i) the depth-averaged horizontal velocity components normal to the open boundaries with the help of an implicit Blumberg and Kantha's (1985) condition, (ii) the three-dimensional velocities normal to these boundaries with the straightforward Blumberg and Mellor's (1987) radiation condition and (iii) zero tangential velocity components. The second modification is the implementation of a near-bed method to improve the computation of SSC and deposition rates at the water-sediment interface. It consists in (i) imposing analytical solutions based on the discontinuous eddy viscosity profile of Grant and Madsen (1979) and the law-of-the-wall in a nested 20-level sub-grid between the bottom and the first vertical COHERENS $\sigma$ grid point and (ii) solving SSC equations through the entire water column from the lower nested grid point to the upper grid point near the free surface. This approach avoids matching problems of the SSC vertical profile particularly tedious during deposition phases around slack waters. Further details on this numerical method are given in Guillou (2007).

Finally, the two-dimensional sediment budget equations are solved with a Lax-Wendroff scheme. This scheme is explicit, ensures the numerical stability of bed evolution and conserves mass (e.g., De Vriend et al., 1993; Berthot and Pattiaratchi, 2006b). 


\section{Application and Discussion}

\subsection{Model Setup}

The schematic test case of an idealised Gaussian shaped headland has been employed in numerous numerical modelling. Signell and Geyer (1990) studied the effects of this schematic headland on the flow dispersion relying on a depth-averaged hydrodynamic model combined with a particle tracking sub-model. Following this numerical approach, Signell and Geyer (1991) exhibited criteria for the occurrence of the flow separation near the tip of the headland and the formation of transient eddies on either sides of the feature. More recently, Signell and Harris (2000) and Berthot and Pattiaratchi (2006b) identified the mechanisms for the formation of headland-associated sandbanks in an oscillatory tidal flow applying a morphological model based on a 3D circulation module. The present application includes substantial part of these model setups.

\subsubsection{Circulation Module}

COHERENS circulation module is implemented on a $50 \mathrm{~km} \times 20 \mathrm{~km}$ rectangle (Fig. 1). There are open boundaries at the western and eastern sides, a free slip wall in the north and a no slip wall in the south. The geometry and tidal conditions are selected from the test case of Signell and Geyer (1991) and Signell and Harris (2000). The idealised Gaussian shaped headland is located in the middle of the southern boundary here referred

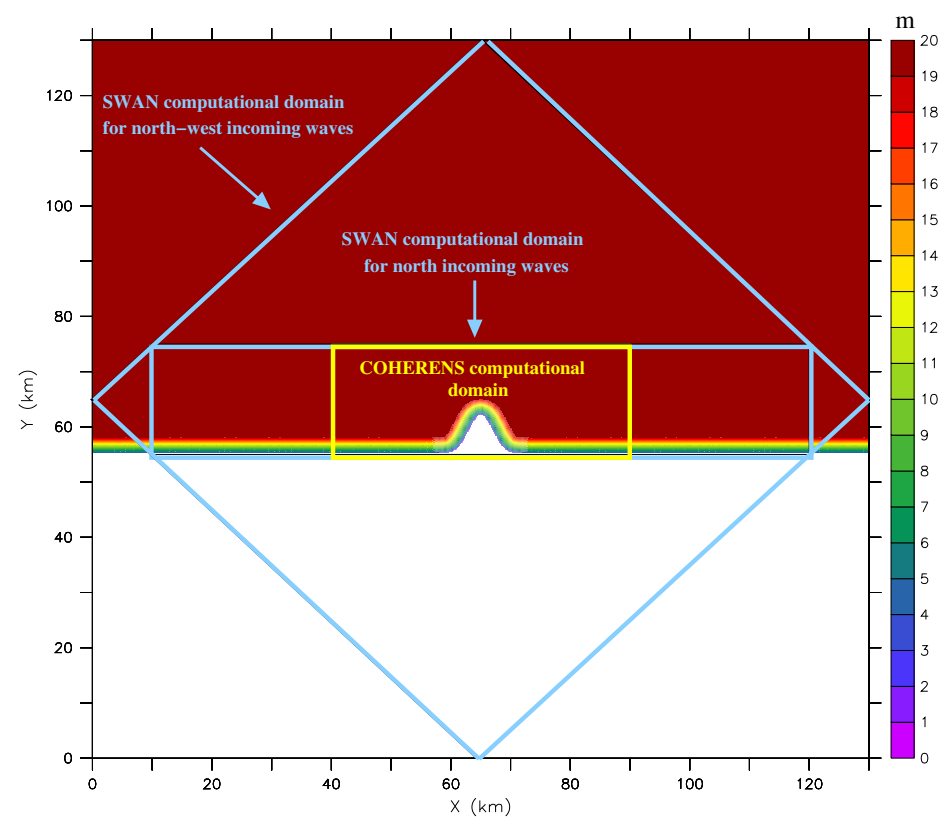

Figure 1: Bathymetry and computational domains of the circulation, the wave propagation and the sediment modules. 
at $x=0$. Its geometry is defined according to the equation

$$
\xi(x)=a \exp \left[-\frac{1}{2}\left(\frac{x}{b}\right)\right]
$$

where $\xi$ defines the coast of the headland along the $y$-direction, $a=8 \mathrm{~km}$ is the offshore extent from the straight baseline and $b=2 \mathrm{~km}$ specifies the alongshore length. The headland is considered to be at a latitude of $51^{\circ} \mathrm{N}$ which corresponds to a Coriolis frequency of $f=1.110^{-4} \mathrm{rd} \mathrm{s}^{-1}$ following Signell and Harris (2000). The water depth is set to $20 \mathrm{~m}$ except near the southern boundary where it decreases linearly to a minimum of $2 \mathrm{~m}$ from a distance of $3 \mathrm{~km}$ towards the coastline. The domain is discretized on a $251 \times 101$ horizontal regular grid with a resolution of $200 \mathrm{~m}$. The circulation model has 10 uniform vertical $\sigma$-grid cells. The time steps for the external and internal modes are 5 and $60 \mathrm{~s}$, respectively. The bottom roughness is set to $z_{0}=0.003 \mathrm{~m}$ (Signell and Harris, 2000). This value is consistent with estimates of the bottom roughness length by Berthot and Pattiaratchi (2006a) near Cape Levillain (Western Australia). The circulation module is driven by a semi-diurnal normal depth-averaged velocity at the western open boundary with an amplitude of $0.5 \mathrm{~m} \mathrm{~s}^{-1}$ (Signell and Geyer, 1991; Signell and Harris, 2000). The Blumberg and Kantha's (1985) implicit condition (section 2.5) is applied at the eastern boundary to allow the tidal wave to leave the domain.

\subsubsection{Waves Propagation Module}

SWAN is set on larger computational domains than the COHERENS area (Fig. 1) as the attenuation of the wave energy towards the coast tends to be overestimated near the lateral open boundaries. Extending the computational domain limits this attenuation in the area of interest. Two domains are thus considered depending on the direction of the waves: (i) a domain extended $110 \mathrm{~km}$ in longitude for north incoming waves and (ii) a $45^{\circ}$ counterclockwise rotated square of $92 \mathrm{~km}$ side for north-west incoming waves. Theses domains are discretized with a horizontal resolution of $200 \mathrm{~m}$ on $551 \times 101$ and $461 \times 461$ horizontal regular grids, respectively. The wave energy density is discretized in 30 exponentially spaced frequencies ranging from $0.0566 \mathrm{~Hz}$ to $1 \mathrm{~Hz}$ and 60 evenly spaced directions $\left(6^{\circ}\right.$ resolution) (e.g., Lin et al., 2002; Hu et al., 2003). To be concordant with modelling conditions for the circulation module, the bottom roughness is set to $z_{0}=0.003 \mathrm{~m}$ in the bed friction dissipation model of Madsen et al. (1988) (section 2.2). SWAN is driven by bi-dimensional (2D) frequency and directional JONSWAP spectrum computed from parameters of significant wave height $h_{s}$, wave direction, period and directional spreading. Waves conditions at the offshore open boundary considers five waves heights $\left(h_{s}=0.3,0.5,1,2\right.$ and $\left.3 \mathrm{~m}\right)$ and two directions (north and north-west). The peak wave period and the wave spreading are set to $10 \mathrm{~s}$ and $20^{\circ}$, respectively.

\subsubsection{Sediment Module}

COHERENS sediment transport and seabed evolution modules (section 2.4) are set on the inner computational domain (Fig. 1) with the same horizontal spatial resolution of $200 \mathrm{~m}$ as for the circulation module. The vertical mesh of 10 uniform vertical $\sigma$-grid cells is completed with 20 above-mentioned (section 2.5) near-bed sublayer $\sigma$-cells. The bottom roughness parameter remains equal to $z_{0}=0.003 \mathrm{~m}$. The bed is initialized with a 1-m thick layer of sediment of uniform single grain size. Following Signell and Harris 
(2000), simulations considered successively (i) bed of silts with a diameter $d_{s}=30 \mu \mathrm{m}$ to compute suspension load and (ii) bed of medium sands with a diameter $d_{b}=250 \mu \mathrm{m}$ to compute bedload. The model is run over a period of 12 days. The circulation model is spun up from a state of rest of 3 tidal cycles before the sediment transport is initiated. The seabed evolution is computed from 4 tidal cycles during 10 days.

\subsection{Results for Tide Alone}

\subsubsection{Tidal Flow and Bottom Shear Stress}

The tidal flow patterns around a Gaussian shaped headland has been the subject of numerous measurements and numerical studies (e.g., Pingree, 1980; Pattiaratchi and Collins, 1987; Geyer and Signell, 1990; Davies et al., 1995; Alaee et al., 2004). A detailed review is available in Berthot and Pattiaratchi (2006b). The present study illustrates the tidal flow characteristics around the headland as the reference situation to estimate the superimposed effects of waves.

Figure 2 displays the tidal depth-averaged horizontal current components $(\bar{u}, \bar{v})$ and the bottom shear-stress $\tau_{b, c}$ at the flood peak and the slack water off the headland tip. As demonstrated by Signell and Geyer (1991), the tidal excursion and the headland and frictional length scales chosen here (section 3.1.1) fall in the range where the flow separation occurred and eddies formed on either sides of the headland. The present results confirm the numerical investigations conducted by Signell and Harris (2000) and Berthot and Pattiaratchi (2006b). Eddies are generated towards the end of the maximum current, advected away from the headland tip at slack water (Fig. 2-c) and rapidly
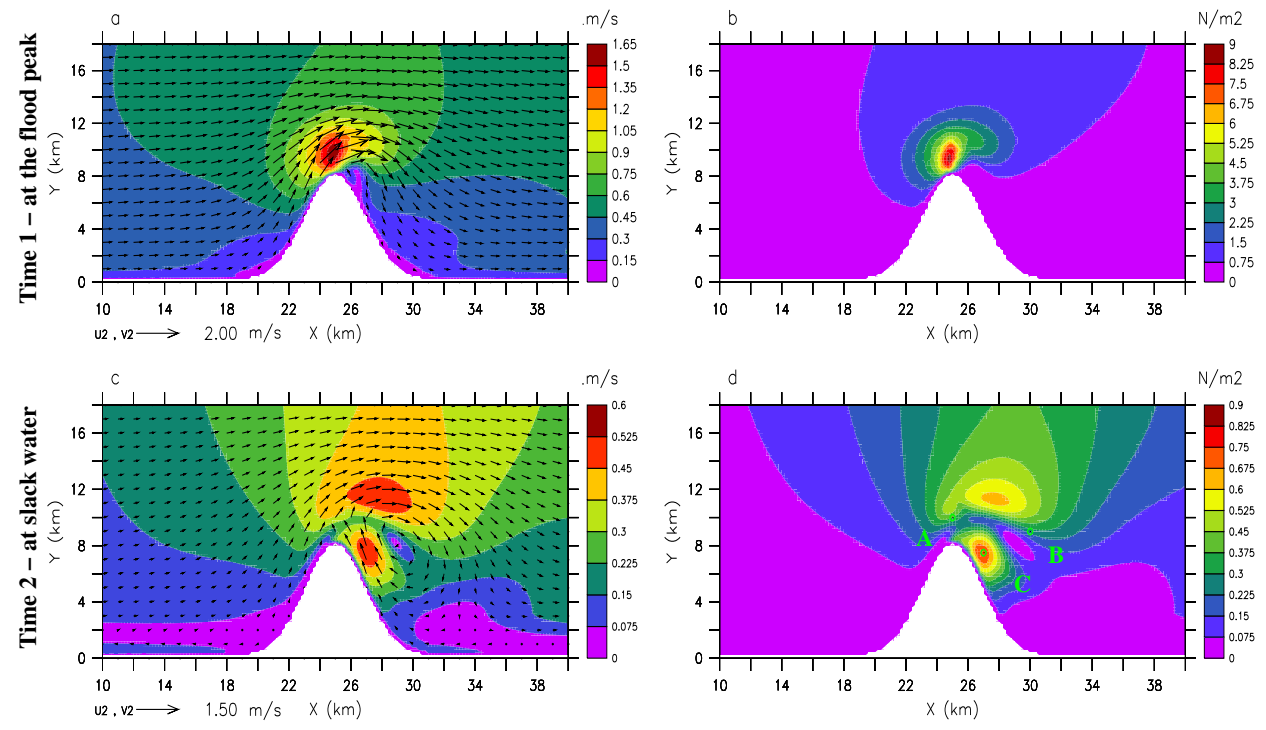

Figure 2: Depth-averaged horizontal current components $(\bar{u}, \bar{v})$ (left) and total bottom shear stress $\tau_{b, c}$ (right) at (up) Time 1 of the flood peak and (bottom) Time 2 of the slack water off the headland tip. Locations A, B and $\mathrm{C}$ of the right-bottom insets indicate where the time series of $\bar{u}, \bar{v}$ and $\tau_{b, c}$ are further investigated in Figure 3. 
dissipated by friction when the flow reversed. No eddy was thus present at times of maximum current off the headland tip (Fig. 2-a) and no interaction occurs between recirculations appearing on either sides of the feature.

The amplitude and direction of the tidal current fit fairly well with Berthot and Pattiaratchi's (2006b) numerical results. The flood is denoted here as the flow being directed from west to east. At the flood peak (Time 1) (Fig. 2-a), the tidal current amplitude exceeds $1 \mathrm{~m} \mathrm{~s}^{-1}$ over a distance of $3 \mathrm{~km}$ from the headland tip with a maximum value of $1.65 \mathrm{~m} \mathrm{~s}^{-1}$. At the slack water (Time 2) (Fig. 2-c), the formation of the eddy is characterized by two areas of high hydrodynamics constraints where the mean velocities are reaching $0.60 \mathrm{~m} \mathrm{~s}^{-1}$. These regions are located on the outer boundaries of the eddy, along the side of the headland and the offshore area, respectively. The reverse of the flow leads to an increase of the tidal current amplitude along the side of the headland to a maximum of $0.80 \mathrm{~m} \mathrm{~s}^{-1}$ (Fig. 3). The flood/ebb asymmetry is naturally evolving between the tip of the headland (point A), the outer eddy boundary (point B) and the side of the feature (point $\mathrm{C}$ ). Whereas the flood and ebb have nearly the same magnitudes off the headland tip (point A) (Figs. 3-a and b), the current predominantly flows towards the coastline in the outer boundary of the eddy (point B) with a peak velocity of $0.77 \mathrm{~m} \mathrm{~s}^{-1}$ against $0.60 \mathrm{~m} \mathrm{~s}^{-1}$ when the circulation reverses (Figs. 3-d and e). The side of the headland (point $\mathrm{C}$ ) is strongly dominated by the acceleration generated along the coast and characterized by a flood phase of 2.5 hours with a peak twice weaker than the ebb peak (Figs. 3-g and h).

An overall good agreement is found between predictions of the tidal bottom shear stress $\tau_{b c}$ and numerical results of Signell and Harris (2000). At the flood peak (Fig. 2-
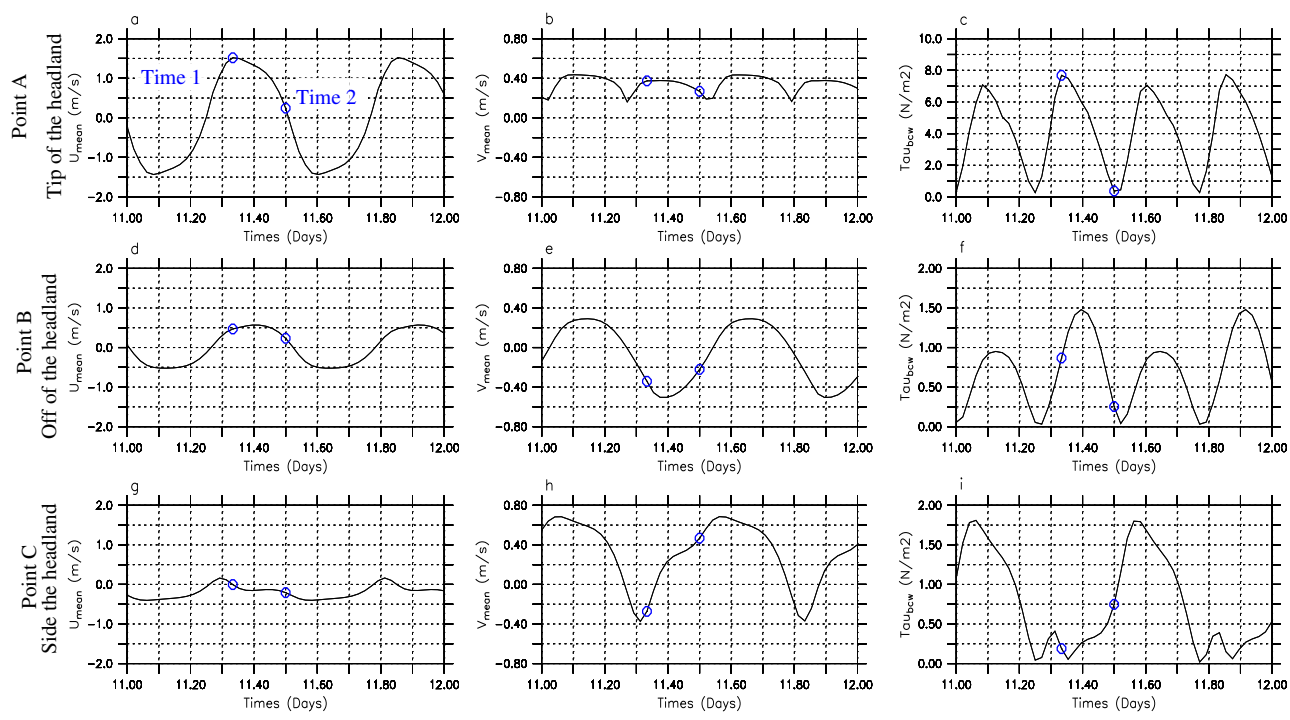

Figure 3: Time series of (left and middle) the horizontal depth-averaged velocity components $(\bar{u}, \bar{v})$ and (right) the total bottom shear stress $\tau_{b, c}$ at points $\mathrm{A}$ off the headland tip $(\mathrm{X}=25 \mathrm{~km}, \mathrm{Y}=10 \mathrm{~km})$, $\mathrm{B}$ away from the feature $(\mathrm{X}=30 \mathrm{~km}, \mathrm{Y}=9 \mathrm{~km})$ and $\mathrm{C}$ along its side $(\mathrm{X}=27 \mathrm{~km}, \mathrm{Y}=7.5 \mathrm{~km})$ (Fig. 2-d). Times 1 and 2 (Fig. 2) are indicated on each time series by a black circle. 
b), the amplitude of $\tau_{b c}$ is above $1.7 \mathrm{~N} \mathrm{~m}^{-2}\left(u_{* c}=4 \mathrm{~cm} \mathrm{~s}^{-1}\right)$ over a distance of $3 \mathrm{~km}$ from the tip of the headland with a maximum value of $9 \mathrm{~N} \mathrm{~m}^{-2}\left(u_{* c}=9.3 \mathrm{~cm} \mathrm{~s}^{-1}\right)$. At the slack water (Fig. 2-d), the maximum values of the bottom shear stress diminish to $0.9 \mathrm{~N} \mathrm{~m}^{-2}$ $\left(u_{* c}=3 \mathrm{~cm} \mathrm{~s}^{-1}\right)$ on the right side of the headland and $0.6 \mathrm{~N} \mathrm{~m}^{-2}\left(u_{* c}=2.4 \mathrm{~cm} \mathrm{~s}^{-1}\right)$ on the northern outer limit of the eddy.

The circulation patterns are broadly similar during the second phase of the tidal cycle on the other side of the headland. Weak differences tend however to appear in relation with a slight frictional damping of the tide as it propagates eastwards from the western open boundary (Signell and Harris, 2000).

\subsubsection{Initial Seabed Evolution for Tide Alone}

The predicted initial seabed evolution by the suspension of silts $\left(d_{s}=30 \mu \mathrm{m}\right)$ (Fig. 4 ) is in good agreement with the first few tidal cycle patterns predicted by Signell and Harris (2000). The patterns of erosion and deposition are thus closely correlated with the fields of the bottom shear stress previously identified (Fig. 2). At the tip of the headland, the acceleration of the westward flow resuspends large quantity of material over a distance of $3 \mathrm{~km}$ from the coastline (Fig. 4-a). Deposition is starting to occur downstream where the flow is decelerating (Figs. 4-b and 4-c). The depositional pattern confined in a thin strip of $500 \mathrm{~m}$ length is initially attached to the headland tip along a direction nearly parallel to its side (Fig. 4-b). As the flow reversed, the acceleration of the current along the side of the headland and its deceleration offshore are leading to the separation of the bed pattern from the coastline and its expansion along a west-eastern direction with a slight offshore orientation (Fig. 4-c). The depositional pattern expands by $10 \%$ and enlarges by a factor of 2 . Mirroring processes happen during the second phase of the tidal cycle on the other side of the headland leading to the development of symmetric depositional features with an area of erosion off the headland tip (Fig. 4-d).

The predicted initial seabed evolution by bedload of medium sands $\left(d_{b}=250 \mu \mathrm{m}\right)$ (Fig. 5) is closely correlated with the spatial divergence of the sand transport rates (Eq. 10) which can roughly be estimated from the spatial gradient of the hydrodynamic constraints (Eq. 6). At the flood peak (Fig. 5-a), a region of strong erosion is thus appearing along the upstream side of the headland and in the vicinity of its tip with a strong depositional area downstream. A lobe of deposition is expanding westward from this central depositional zone following the flow (Fig. 5-b). This expansion continues until slack water. As demonstrated by Berthot and Pattiaratchi (2006b), when the flow reverses (Fig. 5-c), the acceleration of the current along the side of the headland splits this lobe in two creating (i) an extension of the tip $3 \mathrm{~km}$ offshore and (ii) a circular-shaped depositional pattern in the north-eastern part. A mirroring seabed evolution during the second phase of the tidal cycle leads to the development of symmetric depositional features separated by a central depositional spit (Fig. 5-d).

These results confirm in both cases conclusions of Signell and Harris (2000) and Berthot and Pattiaratchi (2006b) exhibiting (i) the negligible influence of the Coriolis forces on the sandbanks formation and (ii) the independence between the centre of the tidal residual eddies and the height of the bank. In the present investigation, the centre of the residual eddies are located $3 \mathrm{~km}$ north of the depositional patterns formed by suspension and $1 \mathrm{~km}$ south of the bed features formed by bedload. A slight asymmetry is however denoted in the size of the initial patterns of deposition in relation to the attenuation of the tidal waves as it propagates eastwards (Signell and Harris, 2000). 

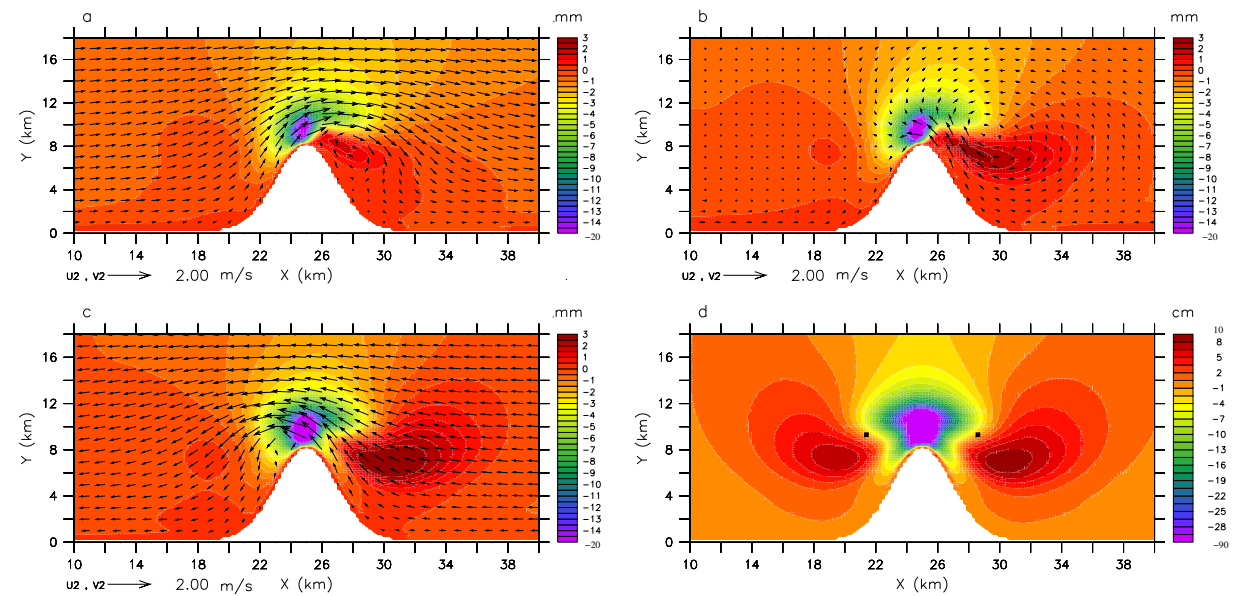

Figure 4: Seabed evolution by suspension load at different time periods of the first tidal cycle (a) during the flood peak, (b) at slack water and (c) during ebb. The bottom-right figure (d) represents the seabed evolution by suspension load over ten days. The two black squares indicate the centre of the tidally-averaged residual eddies.
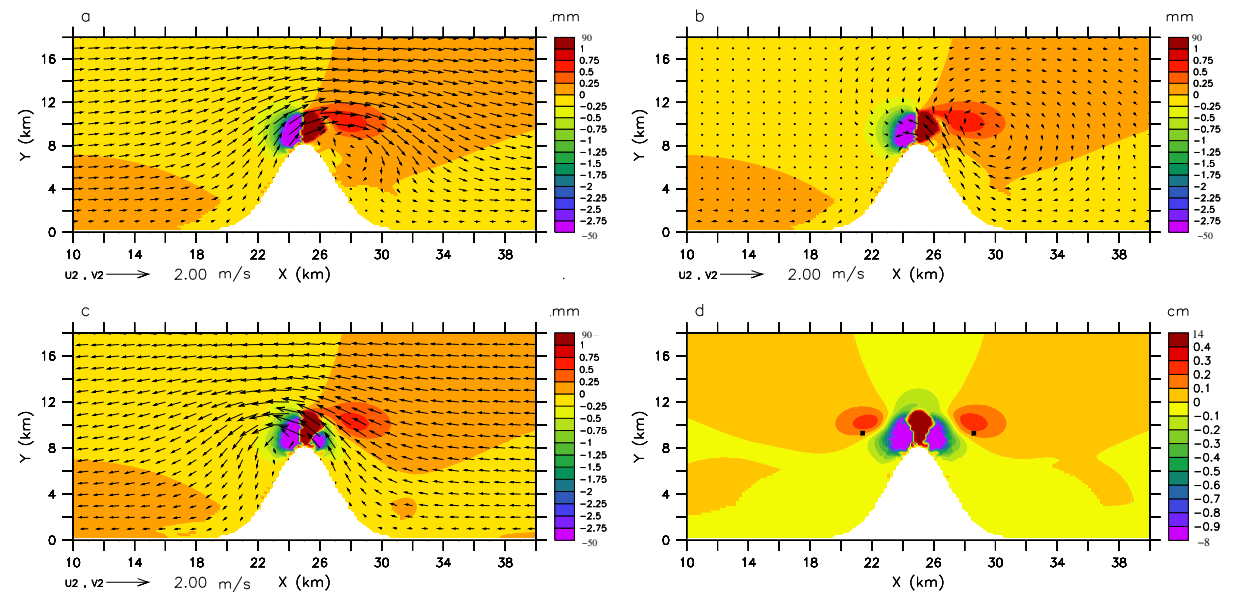

Figure 5: Seabed evolution by bedload at different time periods of the first tidal cycle (a) during the flood peak, (b) at slack water and (c) during ebb. The bottom-right figures (d) represents the seabed evolution by bedload over ten days. The two black squares indicate the centre of the tidally-averaged residual eddies. 


\subsection{Results for Combined Waves and Tide}

\subsubsection{Waves and Tides Hydrodynamics}

Seabed friction dissipation results for the offshore waves conditions considered (section 3.1.2) in a decrease by around $30 \%$ of the significant wave height from the outer offshore open boundary to the straight coastline (Fig. 6). This attenuation is particularly noticeable along the side of the headland where $h_{m 0}$ is reduced by $50 \%$. Refraction leads however to a slight increase by $5-10 \%$ of the wave height off the headland tip. The headland has a major protective effect for oblique waves. This effect is particularly noticeable for the extreme north-west wave conditions of $h_{s}=3 \mathrm{~m}$ with significant waves heights reaching $1.7 \mathrm{~m}$ in the western exposed side of the headland and falling under $0.5 \mathrm{~m}$ in the eastern weak wave energy area.

Waves induce slight modifications of the current fields when compares with the circulation patterns obtained for tide alone (Figs. 2 and 7). Main differences are identified off the headland tip where the action of the waves is the most significant (Fig. 6). In this region, the local increase of the apparent bottom roughness parameter $z_{0 c}$ is leading to a slight decrease of less than $3 \%$ of the current amplitude at the flood peak (Figs. 7-a, $\mathrm{e}, \mathrm{i}$ and $\mathrm{m}$ ). At the slack water (Figs. 7-c, g, $\mathrm{k}$ and o), the increase of $z_{0 c}$ tend to delay the establishment of the eddy and the ebb flow. The consequence is that the current amplitude at that time seems to increase at the outer edge of the eddy and to decrease along the side of the headland when the waves height is increasing.

The total maximum wave and current bottom shear stress $\tau_{b, c \omega}^{\max }$ experiences greater modifications than the current fields. The amplitude of the bottom shear stress is globally increasing. Offshore, the highest values are obtained near the open boundary where the significant waves heights are the most important. At the outer edge of the eddy (Fig. 8-b), the current bottom shear stress $\tau_{b, c}$ reaches $1.5 \mathrm{~N} \mathrm{~m}^{-2}$ at the flood peak for tide alone whereas the total maximum wave and current bottom shear stress $\tau_{b, c \omega}^{\max }$ reaches $2.8 \mathrm{~N} \mathrm{~m}^{-2}$ for north waves of $h_{s}=1 \mathrm{~m}$ and $6.5 \mathrm{~N} \mathrm{~m}^{-2}$ for north waves of $h_{s}=3 \mathrm{~m}$. The
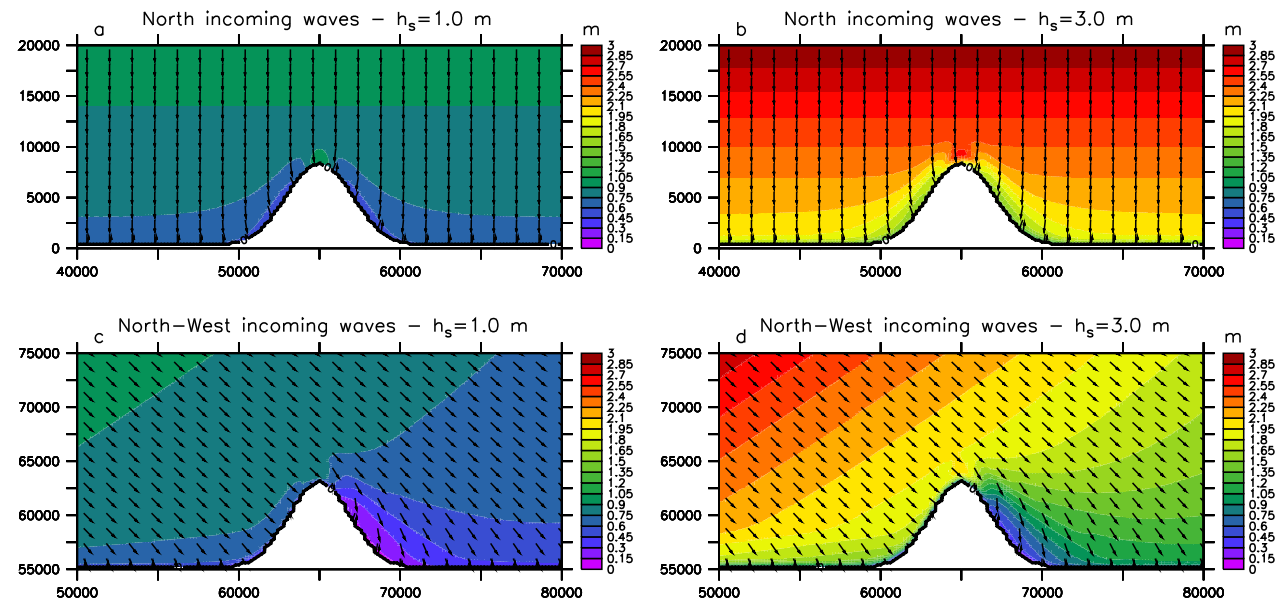

Figure 6: Significant waves heights and directions for the four following waves conditions (a) north direction $-h_{s}=1 \mathrm{~m}$, (b) north direction - $h_{s}=3 \mathrm{~m}$, (c) north-west direction $-h_{s}=1 \mathrm{~m}$ and (d) north-west direction $-h_{s}=3 \mathrm{~m}$. 

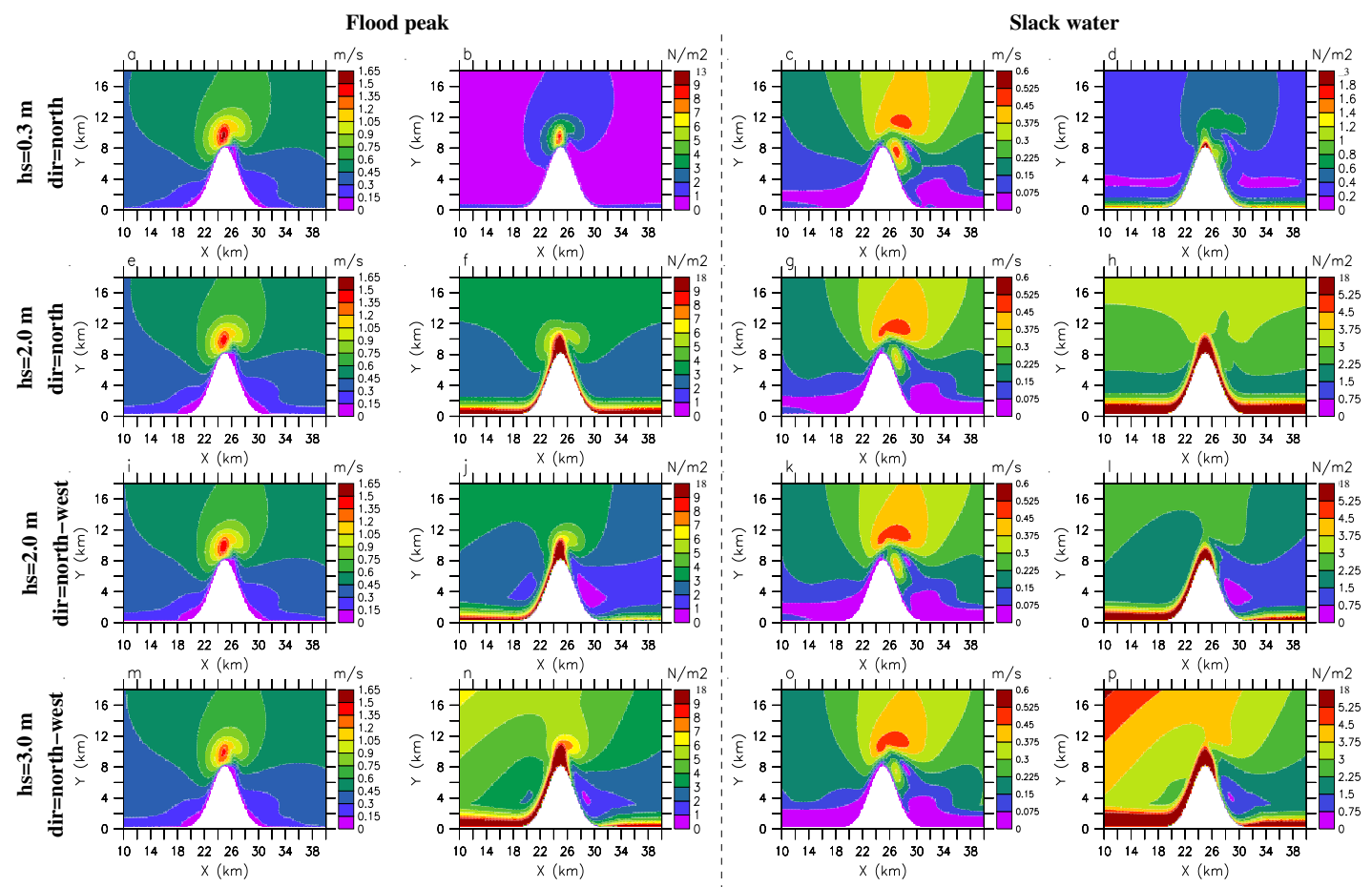

Figure 7: Amplitudes of the depth-averaged horizontal current $\overline{\mathbf{u}}=(\bar{u}, \bar{v})$ and the total maximum wave and current bottom shear stress $\tau_{b, c \omega}^{\max }$ at times of (left) the flood peak and (right) the slack water off the headland tip for the four following waves conditions, north direction $-h_{s}=0.3$ and $2 \mathrm{~m}$, north-west direction $-h_{s}=2$ and $3 \mathrm{~m}$.

maximum values of $\tau_{b, c \omega}^{\max }$ are obtained in a coastal strip of $3 \mathrm{~km}$ width where the shallow water depths exhibit the action of the waves on the seabed. North waves of $h_{s}=3 \mathrm{~m}$ heighten by two the total bottom shear stress off the headland tip (Fig. 8-a). North-west condition of $h_{s}=3 \mathrm{~m}$ gives nearly the same values of $\tau_{b, c \omega}^{\max }$ with a slight increase due to co-linear tidal and wave bottom shear stresses during ebb. The main differences between both conditions (north and north-west) occur naturally on either sides of the headland by lessening the total bottom shear stress in the sheltered area (Figs. 8-b and c).

\subsubsection{Initial Seabed Evolution for Waves and Tide}

The trends of the seabed evolution by the suspension of silts $\left(d_{s}=30 \mu \mathrm{m}\right)$ are given over ten days for the six wave conditions varying in directions between north and northwest and in heights between $h_{s}=1,2$ and $3 \mathrm{~m}$ (Fig. 9). The erosional pattern off the headland tip naturally intensifies when $h_{s}$ increases thus enhancing the height of the depositional patterns on either sides of the headland. North waves are thus exhibiting the slight asymmetry in the initial development of the depositional patterns due to the attenuation of the tidal waves as it propagates eastwards (section 3.2.2). The initial bed features tend to narrow in width and shift their orientation along the side of the headland as waves conditions increases. For significant waves height of $h_{s}=3 \mathrm{~m}$ at the open boundary (Fig. 9-c), the main depositions are confined to a thin band of 

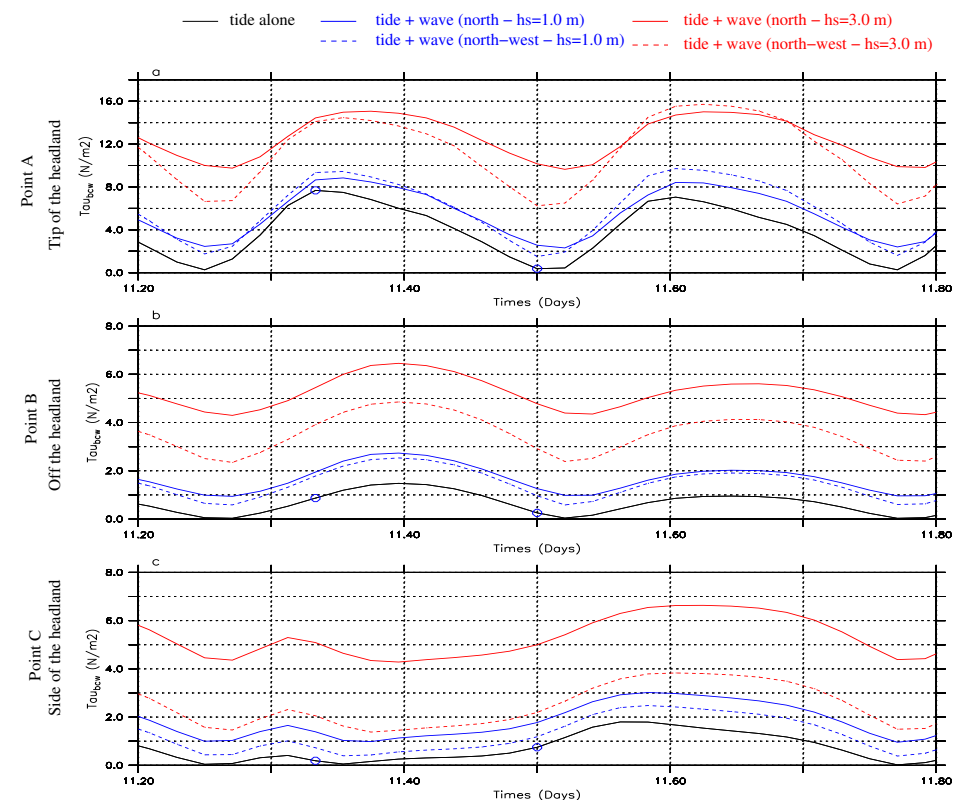

Figure 8: Time series of the current bottom shear stress $\tau_{b, c}$ for tide alone (black line) and the total maximum wave and current bottom shear stress $\tau_{b, c \omega}^{\max }$ for the four following waves conditions, north and north-west directions $-h_{s}=1$ and $3 \mathrm{~m}$, at points A, B and C (Fig. 2).

$900 \mathrm{~m}$ length following the coastline. Nevertheless, the depositional patterns keep a tendency to expand towards the north-west and north-east directions in relation to tideinduced initial seabed evolutions previously identified (section 3.2.2). North-west waves conditions lead to the initial development of a large depositional pattern in the eastern sheltered area whereas limiting its height in the western exposed region. For north-west significant waves height of $h_{s}=3 \mathrm{~m}$ (Fig. 9-f), the western initial bed features are thus characterized by a smooth profile widening in width to $2 \mathrm{~km}$.

For the different waves conditions considered (section 3.1.2), the seabed evolution by the bedload of medium sand $\left(d_{b}=250 \mu \mathrm{m}\right)$ present over ten days slight modifications when compares with results for tide alone. In order to identify these slight evolutions more precisely, the differences with respect to the results for north wave condition of $h_{s}=0.3 \mathrm{~m}$ are displayed for the two north wave conditions of $h_{s}=1$ and $2 \mathrm{~m}$ and the three north-west waves conditions of $h_{s}=1,2$ and $3 \mathrm{~m}$ (Fig. 10). North waves (Figs. $10-b$ and c) increase erosion by bedload on either sides of the headland enhancing deposition over the central spit and the initial bed features. In both cases, the erosion off the tip of the headland limits the extension of the sandy central spit as inferred by Berthot and Pattiaratchi (2006b). North-west waves conditions favor the development of the eastern depositional pattern as the increase of the total maximum bottom shear stress $\tau_{b, c \omega}^{\max }$ along the exposed side of the headland rises the amount of seabed sediment transported to the less eastern exposed area. Finally, the significant waves conditions of $h_{s}=2$ and $3 \mathrm{~m}$ (Figs. 10-c and f) exhibit the initial development of secondary depositional areas farther downstream in the lee of the circular-shaped bed features. This 

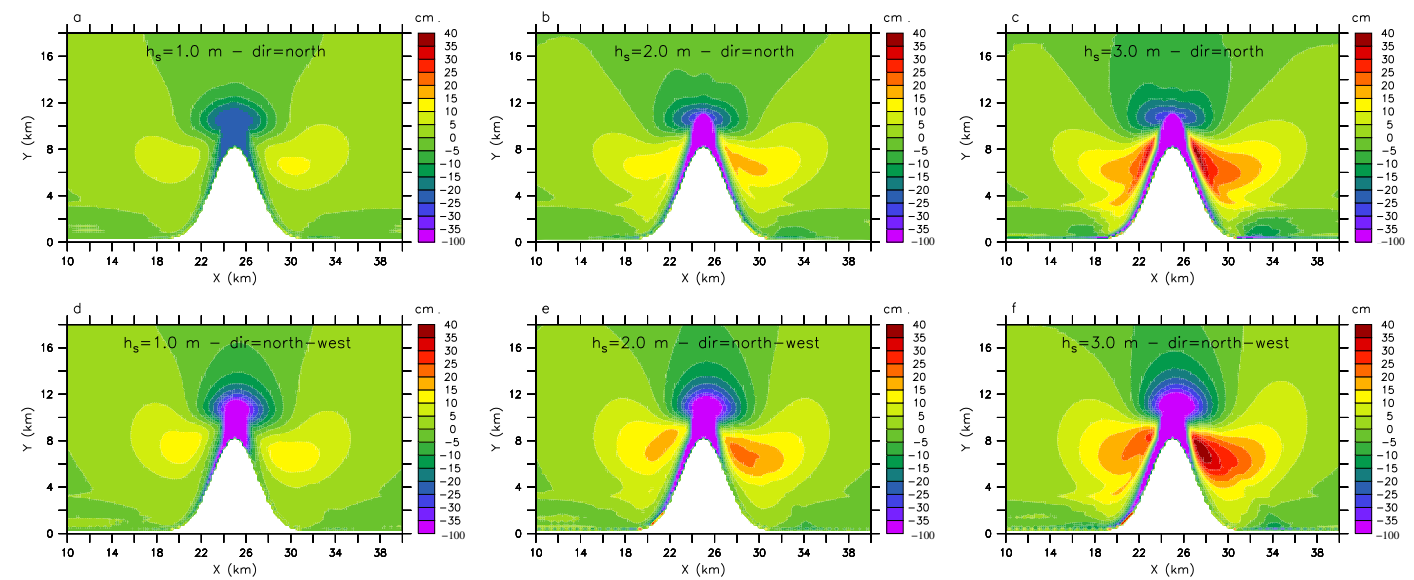

Figure 9: Seabed evolution by suspension load over ten days for the six following waves conditions, north and north-west directions $-h_{s}=1,2$ and $3 \mathrm{~m}$.
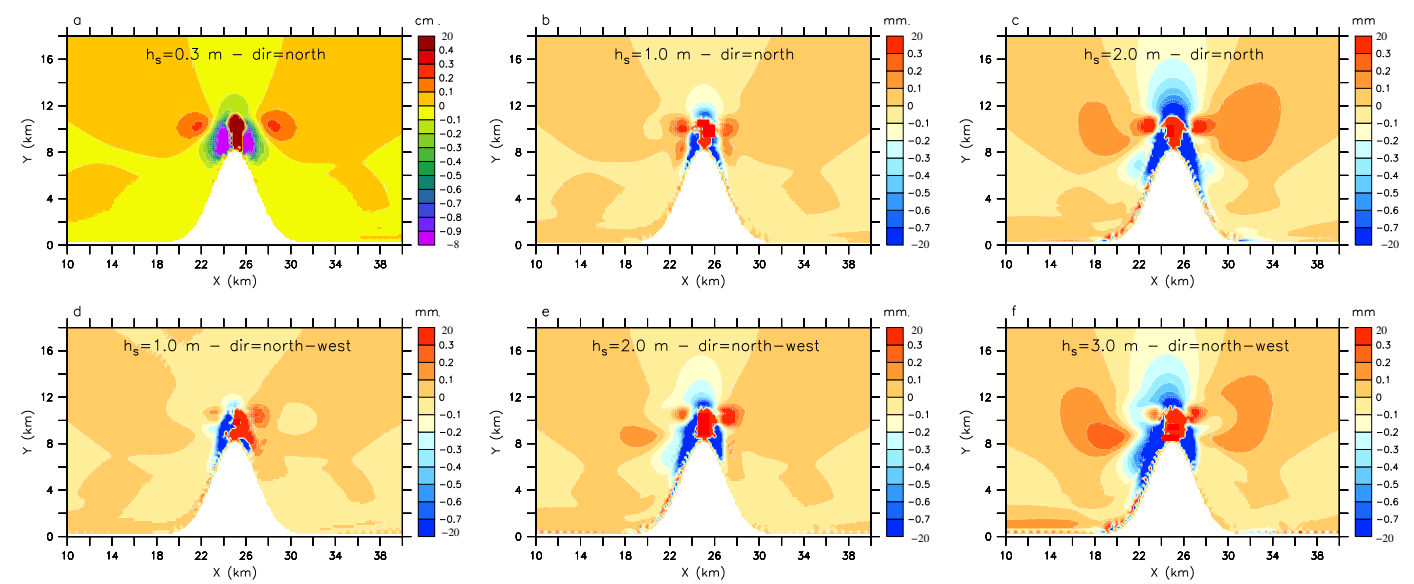

Figure 10: (a) Seabed evolution by bedload over ten days for the north wave condition of $h_{s}=0.3 \mathrm{~m}$ (b-f) Differences with respect to this initial seabed evolution for the five following conditions, north direction $-h_{s}=1$ and $2 \mathrm{~m}$, north-west direction $-h_{s}=1,2$ and $3 \mathrm{~m}$.

initial tendency is consistent with the assumption of Roos et al. (2004) who advanced the fact that waves might damp the growth rate and contribute to the development of lower sandbanks.

Waves have an impact in the asymmetrical development of headland-associated bed features on short time scales. This effect is particularly noticeable for the seabed evolution by suspension load of silts. Nevertheless, these numerical results should be considered taking into account the limitations of the short-term modelling. Indeed, in tidedominated conditions, the long-term development of the sandbanks present differences with the first few tidal cycle patterns of erosion and deposition. The formation of the 
sandbanks by suspension is thus characterized by a migration away from the headland tip along its shoreward sides as the source supply of sediment is depleted (Signell and Harris, 2000). The formation of the sandbanks by bedload is very sensitive to the interaction between the tidal flow and the bed features which modify the initial circular shape into a more elongated shape (Berthot and Pattiaratchi, 2006b). Such differences are liable to occur in the long term development of sandbanks under the combined action of waves and tide. Whereas the same tendencies may appear in relation to the tide induced formation of sandbanks, a complex modelling is required to approach thoroughly the interactions between the waves, the currents, the sediment transport and the seabed evolution on long time scales.

\section{Conclusions}

A morphological model has been applied to an idealised Gaussian shaped headland to determine the combined effects of waves and tide on the initial development of associated linear sandbanks. The simulation is based on the coupling of the wave propagation module SWAN, the 3D circulation module COHERENS and a single component sediment transport and seabed evolution module. The coupling is restricted to the effects of the interaction between the wave and current bottom boundary layers. This interaction leads to enhancements of the levels of turbulence near the bottom and the total maximum shear stress exerted on seabed sediments. The modifications of the waves components by the current and the free surface elevation as well as the generation of currents by waves are ignored. Computations are performed considering successively the initial seabed evolution by the suspension of silts $\left(d_{s}=30 \mu \mathrm{m}\right)$ and the bedload of medium sands $\left(d_{b}=250 \mu \mathrm{m}\right)$. The main outcomes of the present study are the following.

(1) Mappings of the depth-averaged currents and the bottom shear stresses in combined waves and tidal current conditions are produced. The interaction between the wave and current bottom boundary layers has a negligible impact on the tidal circulation patterns. The increase of the apparent roughness parameter felt by the current above the wave boundary layer reduces by $3 \%$ the intensity of the current off the headland tip and slightly delays the formation of the eddies on either sides of the headland. The total maximum wave and current bottom shear stress experiences greater modifications with a significant increase of its amplitude in shallow water depth and off the headland tip.

(2) Waves substantially modify the shape and orientation of the initial depositional patterns developed by the suspension of silts $\left(d_{s}=30 \mu \mathrm{m}\right)$. Increasing the waves heights and the bottom orbital velocities result in a narrowing of the width of these bed features and a reorientation along the side of the headland. North-west waves conditions contribute on a short-time scale to the development of a well-developed depositional area in the eastern side of the headland limiting its growth in the western exposed region.

(3) Waves weakly impact the initial development of sandbanks by the bedload of medium sands $\left(d_{b}=250 \mu \mathrm{m}\right)$. The increase of erosion on either sides of the headland favors the initiation of symmetric circular-shaped bed features and the growth of the central depositional spit prolonging the headland tip. Nevertheless, the northern spit extension is limited by offshore waves erosion. North-west waves 
conditions slightly favor the initial development of the depositional pattern in the sheltered area.

The present study is restricted to the initial development of sandbanks. The seabed evolutions are considered as trends of the erosional and depositional patterns in response to the hydrodynamic forcings of tide alone and combined tide and waves. Although this approach provides interesting insights into the asymmetrical development of headland-associated sandbanks, the interactions between the seabed and the hydrodynamics modify the geometry of the bed features for longer morphological runs (Signell and Harris, 2000; Berthot and Pattiaratchi, 2006b). Modelling the long term formation of headland-associated sandbanks under the combined actions of waves and tide will require to integrate the interactions between the changes in the bathymetry and the circulation and the waves fields. Moreover, whereas the interaction between the wave and current bottom boundary layers explain substantial part of the waves action in the asymmetrical development of the sandbanks, long-term modelling may require the integration of complementary interactions such as the effects of the current on the waves field or the generation of currents by waves. Further prospective of this research will consist in incorporating a heterogeneous bottom sediments distribution and the superimposed effects of wind meteorological forcings. These numerical developments will aim at a realistic application of the model like in the case of Cape Levillain to provide a better understanding of the Levillain Shoal's formation.

\section{Acknowledgements}

Computations were performed on the computer facilities CAPARMOR (CAlcul PARallèle Mutualisé pour l'Océanographie et la Recherche). The present paper is a contribution to the CETMEF-IUEM joint research program MEMPHYS (MEsure et Modélisation des Processus HYdrodynamiques et Sédimentaires dans les écosystèmes côtiers).

\section{References}

Alaee, M., Ivey, G., Pattiaratchi, C., 2004. Secondary circulation induced by flow curvature and Coriolis effects around headlands and islands. Ocean Dynamics 54 (1), pp. 27-38.

Bastos, A. C., Paphitis, D., Collins, M., 2004. Short-term dynamics and maintenance processes of headland-associated sandbanks: Shambles Bank - English Channel (UK). Estuarine, Coastal and Shelf Science 59 (1), pp. 33-47.

Battjes, J., Janssen, J., 1978. Energy loss and set-up due to breaking of random waves. In: Proceedings of 16th International Conference of Coastal Engineering. Vol. ASCE. pp. 569-587.

Berthot, A., Pattiaratchi, C., 2005. Maintenance of headland-associated linear sandbanks: modelling the secondary flows and sediment transport. Ocean Dynamics 55, pp. 526-540.

Berthot, A., Pattiaratchi, C., 2006a. Field measurements of the three-dimensional current structure in the vicinity of a headland-associated linear sandbank. Continental Shelf Research 26, pp. $295-317$.

Berthot, A., Pattiaratchi, C., 2006b. Mechanisms for the formation of headland-associated linear sandbanks. Continental Shelf Research 26, pp. 987-1004.

Blumberg, A. F., Kantha, L. H., 1985. Open boundary conditions for circulation models. Journal of Hydraulic Engineering 11, pp. 237-255.

Blumberg, A. F., Mellor, G. L., 1987. A description of a three-dimensional coastal ocean circulation model. In: Three-Dimensional Coastal Ocean Models, Coastal and Estuarine Sciences. Vol. 4. American Geophysical Union, Washington DC, pp. 1-16.

Booij, N. R. C., Ris, R. C., Holthuijsen, L. H., 1999. A third generation wave model for coastal regions, part i, model description and validation. Journal of Geophysical Research 104 (C4), pp. 7649-7666. 
Boussinesq, J., 1823. Essai sur la théorie des eaux courantes. Mémoire présenté par divers savants à l'Académie des Sciences de Paris. Vol. 23. Paris, pp. 380-398.

Boussinesq, J., 1903. Théorie analytique de la chaleur, mise en harmonie avec la thermodynamique et avec la théorie mécanique de la lumière. Gauthiers-Villars, Paris.

Celik, I., Rodi, W., 1988. Modelling suspended sediment transport in non-equilibrium situations. Journal of Hydraulic Engineering 10 (114), pp. 1157-1119.

Celik, I., Rodi, W., 1991. Suspended sediment-transport capacity for open channel flow. Journal of Hydraulic Engineering 2 (117), pp. 191-204.

Chapalain, G., Thais, L., 2000. Tide, turbulence and suspended sediment modelling in the eastern English Channel. Coastal Engineering 41, pp. 295-316.

Davies, P., Dakin, J., Wolanski, E., 1995. Eddy formation behind a coastal headland. Journal of Coastal Research 11, pp. 154-167.

De Vriend, H., Zyserman, J., Nicholson, J., Roelvink, J., Pechon, P., Southgate, H., 1993. Medium term 2DH coastal area modelling. Coastal Engineering 21, pp. 193-224.

Dyer, K. R., Huntley, D. A., 1999. The origin, classification and modelling of sand banks and ridges. Continental Shelf Research 19, pp. 1285-1330.

Ferentinos, G., Collins, M., 1980. Effects of shoreline irregularities on a rectilinear tidal current and their significance in sedimentation processes. Journal of Sedimentary Petrology 50 (4), pp. 1081-1094.

Geyer, R. W., 1993. Three-dimensional tidal flow around headlands. Journal of Geophysical Research 98 (C1), pp. 955-966.

Geyer, R. W., Signell, R., 1990. Measurements of tidal flow around a headland with a shipboard acoustic doppler current profiler. Journal of Geophysical Research 95, pp. 3189-3197.

Grant, W. D., Madsen, O. S., 1979. Combined wave and current interaction with a rough bottom. Journal of Geophysical Research 84 (C4), pp. 1797-1808.

Guillou, N., 2007. Rôles de l'hétérogénéité des sédiments de fond et des interactions houle-courant sur l'hydrodynamique et la dynamique sédimentaire en zone subtidale - applications en Manche orientale et à la pointe de la Bretagne. Ph.D. thesis, Université de Bretagne Occidentale, 469 pp.

URL http://tel.archives-ouvertes.fr/tel-00376679/en/

Guillou, N., Chapalain, G., Thais, L., 2009. Three-dimensional modelling of tide-induced suspended transport of seabed multicomponent sediments in the eastern English Channel. Journal of Geophysical research 114 (C07025).

Guillou, N., Chapalain, G., 2010. Numerical simulation of tide-induced transport of heterogeneous sediments in the English Channel. Continental Shelf Research 30, pp. 806-819.

Hu, K., Ding, P., Zhu, S., Kong, Y., 2003. Numerical simulation of typhoon waves around the waters of the Yangtze estuary - a case study of typhoon rusa and typhoon sinlaku. In: International Conference on Estuaries and Coasts. pp. 929-936.

Launder, B. E., Spalding, D. B., 1974. The numerical computation of turbulent flows. Computer Methods in Applied Mechanics and Engineering 3, pp. 269-289.

Lavelle, J. W., Mofjeld, H. O., Baker, E. T., 1984. An in situ erosion rate for fine-grained marine sediment. Journal of Geophysical Research 89, pp. 6543-6552.

Lick, W., 1982. Entrainment, deposition, and transport of fine-grained sediments in lakes. Hydrobiologia 91, pp. 31-40.

Lin, W., Sanford, L. P., Suttles, S. E., 2002. Wave measurement and modeling in Chesapeake Bay. Continental Shelf Research 22, pp. 2673-2686.

Luyten, P. J., Jones, J. E., Proctor, R., Tabor, A., Tett, P., Wild-Aden, K., 1999. COHERENS: A COupled Hydrodynamics-Ecological model for REgioNals and Shelf seas - Part III Model Description (Available on CD-ROM via http://www.mumm.ac.be/coherens). Management Unit of the North Sea Mathematical Models, Belgium, 200 pp.

Madsen, O. S., Poon, Y. K., Graber, H. C., 1988. Spectral wave attenuation by bottom friction: Theory. In: Proc. 21th Int. Conf. Coastal Engineering, ASCE. pp. 492-504.

Pattiaratchi, C., Collins, M., 1987. Mechanisms for linear sandbank formation and maintenance in relation to dynamical oceanographic observations. Progress in Oceanography 19, pp. 117-166.

Pingree, R. D., 1978. The formation of the Shambles and other banks by tidal stirring of the seas. Journal of the Marine Biological Association 58, pp. 211-226.

Pingree, R. D., 1980. Physical oceanography of the celtic sea and english channel. In: F.T., B., Collins, M., (eds), K. M. (Eds.), The north-west European Shelf seas: the sea bed and the sea in motion. II. Physical and chemical Oceanography, and physical resources. Oceanography series 24B. Elsevier, pp. 415-465.

Roos, P., Hulscher, S., Knaapen, M., Damme, R. V., 2004. The cross-sectional shape of tidal sandbanks: 
modeling and observations. Journal of Geophysical Research 109, F02003.

Signell, R. P., Geyer, W. R., 1990. Numerical simulation of tidal dispersion around a coastal headland. Coastal and Estuarine Studies 38, pp. 211-222.

Signell, R. P., Geyer, W. R., 1991. Transient eddy formation around headlands. Journal of Geophysical Research 96 (C2), pp. 2561-2575.

Signell, R. P., Harris, C. K., 2000. Modeling sand bank formation around tidal headlands. In: Spaulding, M. L., Blumberg, A. F. (Eds.), 6th International Conference on Estuarine and Coastal Modeling. New Orleans.

Smagorinsky, J., 1963. General circulation experiments with the primitive equations, i, the basic experiments. Monthly Weather Review 91, pp. 99-164.

Smith, J. D., Lean, S. R. M., 1977. Spatially averaged flow over a wavy surface. Journal of Geophysical Research 12 (82), pp. 1735-1746.

Soulsby, R., 1997. Dynamics of marine sands. H. R. Wallingford, 249 pp.

Soulsby, R. L., Whitehouse, R. J. S. W., 1997. Thresholds of sediment motion on coastal environments. In: Proceedings Pacific Coasts and Ports '97 Conference. University of Canterbury, New Zealand, pp. $149-54$.

SWAN team, 2009. SWAN cycle III version 40.72 AB - Scientific and Technical Documentation. Tech. rep., Delft University of Technology, $107 \mathrm{pp}$.

Van Rijn, L., 1986. Mathematical modelling of suspended sediment in non-uniform flows. Journal of Hydraulic Engineering 112, pp. 433-455.

Westrich, B., 1976. Simulation of mass exchange in dead zones for steady and unsteady flow conditions: Proc. In: International Symposium, Unsteady Flow in Open Channels. Newcastle-Upon-Tyne, v. G3-23. 